\title{
BMJ Open Association between tissue oxygenation and myocardial injury in patients undergoing major spine surgery: a prospective cohort study
}

Katrine Feldballe Bernholm (1) ,1,2 Christian S. Meyhoff (1D , ${ }^{2,3,4}$ Philip Bickler (1) ${ }^{1}$

To cite: Bernholm KF, Meyhoff CS, Bickler P. Association between tissue oxygenation and myocardial injury in patients undergoing major spine surgery: a prospective cohort study. BMJ Open 2021;11:e044342. doi:10.1136/ bmjopen-2020-044342

- Prepublication history for this paper is available online. To view these files, please visit the journal online (http://dx.doi org/10.1136/bmjopen-2020044342).

Received 01 September 2020 Accepted 27 July 2021

\section{Check for updates}

(c) Author(s) (or their employer(s)) 2021. Re-use permitted under CC BY-NC. No commercial re-use. See rights and permissions. Published by BMJ.

${ }^{1}$ Department of Anesthesia and Perioperative Care, University of California, San Francisco,

California, USA

${ }^{2}$ Department of Anaesthesia and Intensive Care, Bispebjerg Hospital, Copenhagen, Denmark

${ }^{3}$ Copenhagen Center for Translational Research, Bispebjerg and Frederiksberg Hospital, Copenhagen University Hospital, Copenhagen, Denmark ${ }^{4}$ Department of Clinical Medicine, University of Copenhagen, Copenhagen, Denmark

Correspondence to Dr Katrine Feldballe Bernholm; bernholm3@hotmail.com

\section{ABSTRACT}

Objective To describe the association between intraoperative tissue oxygenation and postoperative troponin elevation in patients undergoing major spine surgery. We hypothesised that a decrease in intraoperative skeletal muscle tissue oxygenation $\left(\mathrm{SmO}_{2}\right)$ was associated with the peak postoperative cardiac troponin value.

Design This is a prospective cohort study.

Setting Single-centre, University of California San Francisco Medical Center.

Participants Seventy adult patients undergoing major elective spine surgery.

Primary and secondary outcome measures Highsensitivity troponin T (hsTnT) was measured in plasma preoperatively and on the first and second day after surgery to assess the primary outcome of peak postoperative hsTnT. Secondary outcomes included MINS and intensive care unit (ICU) admission within 30 days. Skeletal cerebral tissue oxygenation and $\mathrm{SmO}_{2}$ was measured continuously with near-infrared spectroscopy during surgery. The primary exposure variable was timeweighted area under the curve (TW AUC) for $\mathrm{SmO}_{2}$. Results Mean age was 65 (33-85) years and 59\% were female. No significant association was found between TW AUC for $\mathrm{SmO}_{2}$ and peak hsTnT (Spearman's correlation, $\left.r_{s}=0.17, p=0.16\right)$. A total of $28(40 \%)$ patients had MINS. ICU admission occurred in $14(40 \%)$ in lower vs $25(71 \%)$ in upper half of patients based on TW AUC for $\mathrm{SmO}_{2}$, $\mathrm{p}=0.008$.

Conclusions Decrease in $\mathrm{SmO}_{2}$ was not a statistically significant predictor for peak troponin value following major spine surgery but is a potential predictor for other postoperative complications.

Trial registration number NCT03518372.

\section{INTRODUCTION}

Major non-cardiac surgery is associated with significant risks of postoperative complications which are sometimes asymptomatic such as covert stroke ${ }^{1}$ and myocardial infarction and injury. ${ }^{2}$ Cardiovascular events are the leading cause of morbidity and mortality ${ }^{3}$ with myocardial injury after non-cardiac surgery (MINS) being a major contributor to further postoperative complications. ${ }^{4-7}$ MINS

\section{Strengths and limitations of this study}

- Prospective observational study including 70 patients undergoing major spine surgery.

- Contributing knowledge to potential predictors for myocardial injury and clinical implications of tissue oxygenation monitoring.

- Applying skeletal muscle tissue oxygenation as primary predictor, decreasing risk of cerebral autoregulation modification of outcomes.

- There is no clinical consensus of absolute threshold for tissue hypoxaemia, thus, population median for skeletal muscle tissue oxygenation was used as cutoff in this study.

is frequently caused by ischaemia and can be diagnosed from elevated postoperative highsensitivity cardiac troponin, in the absence of non-ischaemic factors for troponin elevation. ${ }^{8}$ The 30 -day mortality is increased up to eightfold in patients with covert stroke compared with matched controls ${ }^{9}$ and stroke occurs in $9 \%$ of patients with MINS, making it a substantial public health problem. ${ }^{10}$ Peak postoperative cardiac troponin has a linear association with 30 -day mortality. ${ }^{7}$ Each year, 8 million surgical patients worldwide suffer from MINS but there is sparse knowledge about triggering causes and contributing factors to the magnitude of peak postoperative cardiac troponin. ${ }^{511}$

Intraoperative tissue oxygen desaturation is common in patients undergoing major spine surgery ${ }^{12}$ probably because of the substantial blood loss and haemodynamic changes that occur in this type of operation. Tissue oxygenation $\left(\mathrm{StO}_{2}\right)$ can be measured non-invasively with near-infrared spectroscopy (NIRS). Previous studies found that a decrease in intraoperative $\mathrm{StO}_{2}$ was associated with wound infection, stroke and renal failure, ${ }^{13}$ and that decrease in skeletal muscle tissue oxygenation $\left(\mathrm{SmO}_{2}\right)$ was a stronger 
predictor for these complications than cerebral tissue oxygenation $\left(\mathrm{ScO}_{2}\right)$ in spine surgery. ${ }^{12}$ However, current knowledge of how $\mathrm{StO}_{2}$ affects other important clinical outcomes, including MINS, is lacking. In this prospective cohort study, we hypothesised that a decrease in $\mathrm{SmO}_{2}$ was associated with higher peak postoperative high-sensitivity troponin $\mathrm{T}$ (hsTnT). The primary exposure variable was time-weighted area under the curve (TW AUC) for $\mathrm{SmO}_{2}$ and the primary outcome was peak postoperative hsTnT. This study was conducted with the aim of examining the association between intraoperative $\mathrm{StO}_{2}$ and postoperative troponin elevation in patients undergoing major spine surgery.

\section{METHODS}

This prospective cohort study was conducted at the University of California, San Francisco (UCSF). This manuscript adheres to the applicable Strengthening the Reporting of Observational Studies in Epidemiology guidelines.

\section{Patients}

The patients were adults ( $\geq 18$ years) undergoing elective spine surgery at UCSF from January to May 2018. The surgeries selected were scheduled to last for more than 2 hours and included instrumentation. Exclusion criteria were: American Society of Anesthesiologists Physical Status Classification System score $>$ IV, surgery for tumour or infection, emergent or urgent surgery.

\section{Data collection}

Patient characteristics, comorbidities, preoperative physical status and postoperative complications were extracted from the electronical medical record (KFB). Data were collected at two time points: prior to surgery and 30 days after surgery. A follow-up phone call to the patient was made 30 days after surgery to verify postoperative outcomes. Baseline values were defined as the preincision value. Intraoperative values were defined as data from incision to end of procedure when last suture was placed. Study data were managed using the REDCap (Research Electronic Data Capture) tools hosted at UCSF.

\section{Tissue oximetry}

$\mathrm{StO}_{2}$ was monitored using a tissue oximeter based on NIRS (FORE-SIGHT Elite, CASMED, Branford, Connecticut, USA). Cerebral and leg skeletal muscle oxygenation was monitored via two cables connected to adhesive probes provided by the manufacturer. Probes were placed after tracheal intubation and a baseline was measured from placing of probe to incision. One probe was placed on the left side on the upper forehead to monitor onesided frontal cortex $\mathrm{ScO}_{2}$. The second probe was placed on the left tibialis anterior muscle, four fingers below the tibial tuberosity and two fingers lateral to the anterior edge of the tibial shaft, to monitor the $\mathrm{SmO}_{2}$ of the lower leg muscle. The oximeter generated a data point every 2 seconds. The anaesthesia team was blinded to the oximeter. Data from the oximeter were used for $\mathrm{StO}_{2}$ indices derivation. Indices were maximum, minimum, median and TW AUC for $\mathrm{SmO}_{2}$ and $\mathrm{ScO}_{2}$, respectively. The primary exposure variable was TW AUC for $\mathrm{SmO}_{2}$. TW AUC was calculated for each participant as the area below the intraoperative median for the study population and divided by length of surgery. This was chosen because there is no international consensus on a universal baseline level or normal range for $\mathrm{StO}_{2}$.

\section{Troponin measurements}

A total of three blood samples for hsTnT were drawn. First sample was drawn by the anaesthesiologist in the operating room after placement of the arterial line prior to surgery. Second and third sample were drawn by a phlebotomist or nurse the first and second day after surgery, respectively. After the blood was drawn, the sample was centrifuged immediately and the plasma was divided into two cryo collecting tubes and placed in a $-80^{\circ} \mathrm{C}$ freezer for storage. All plasma samples were sent to a specialised laboratory at Hennepin Medical Center (Minneapolis, Minnesota, USA) to be analysed for the Roche fifth generation, Elecsys hsTnT assay after the study was completed. The data collector was blinded to the results of hsTnT and laboratory personnel analysing the blood samples were blinded to patient data. Medical records and perioperative information (eg, ECG, laboratory values) were reviewed for patients with troponin elevation, to exclude a non-ischaemic aetiology. ${ }^{8}$

\section{Outcomes}

The primary outcome was defined as postoperative peak high-sensitivity cardiac troponin $\mathrm{T}$ (hsTnT). A secondary related outcome was MINS, initially defined as $\mathrm{hsTnT} \geq 14 \mathrm{ng} / \mathrm{L}^{14}$ with factors for non-ischaemic aetiology excluded (eg, sepsis, kidney failure, heart failure). This MINS definition was registered at ClinicalTrials.gov, but during the course of the study and prior to hsTnT analysis of the blood samples, new data were published, where MINS was defined as an elevated postoperative hsTnT (ie, 20 to $<65 \mathrm{ng} / \mathrm{L}$ with an absolute change $\geq 5 \mathrm{ng} / \mathrm{L}$ or a single $\mathrm{hsTnT} \geq 65 \mathrm{ng} / \mathrm{L}$ ) with factors for non-ischaemic aetiology excluded (eg, sepsis, kidney failure, heart failure). ${ }^{8}$ We, therefore, updated the protocol to the latter and current MINS definition. Other secondary outcomes were myocardial infarction, non-fatal cardiac arrest, new-onset arrhythmia (defined as new atrial fibrillation or other treatment requiring arrhythmia), heart failure, transient cerebral ischaemia, symptomatic stroke, sepsis, surgical site infection, pulmonary complications (including pulmonary infection, pneumothorax, atelectasis, pulmonary embolus and other pulmonary complication), creatinine elevation $(>1.3 \mathrm{mg} / \mathrm{dL}$ for men and $>1.1 \mathrm{mg} / \mathrm{dL}$ for women $)$, intensive care unit (ICU) admission, length of hospital stay and mortality, all within 30 days after surgery. In addition, we analysed a composite outcome that consisted of all above mentioned postoperative complications. 


\section{Sample size}

Sample size calculations were based on clinical data and previous studies investigating $\mathrm{StO}_{2}$ as an outcome for postoperative complications. ${ }^{12} 13$ These studies evaluated all types of complications as primary outcome. Mean (SD) TW AUC for $\mathrm{SmO}_{2}$ was $1.59 \% \times \min \times \mathrm{h}^{-1}$ (2.35). ${ }^{12}$ We estimated a minimal clinically relevant difference to be a $36 \%$ increase in TW AUC for $\mathrm{SmO}_{2}$ for participants with high peak hsTnT (with a cut-off of $14 \mathrm{ng} / \mathrm{L}$ based on the 99 th percentile of a healthy population $)^{15}$ compared with participants with low peak hsTnT. Using a power of $80 \%$ and a significance level of 0.05 , a sample size of 68 participants for this study was needed. We anticipated a low number of drop-outs, as the study design was observational, resulting in a total sample size of 70 participants.

\section{Statistical analysis}

Results are presented as mean $\pm \mathrm{SD}$ and median (IQR) when appropriate. Revised Cardiac Risk Index (RCRI) and corresponding risk of cardiac complications at 30 days after surgery were computed according to current criteria. ${ }^{16}$ Postoperative outcomes were compared stratifying the study population in two groups by median TW AUC for $\mathrm{SmO}_{2}$. Comparison between groups were based on $\chi^{2}$ tests for categorical variables, analysis of variance and Wilcoxon rank-sum test.

The primary analysis of the association between TW AUC for $\mathrm{SmO}_{2}$ and peak hsTnT was tested by Spearman correlation analysis. Univariable and multivariable logistic regression models were used in secondary analyses to examine the associations of baseline characteristics, intraoperative variables and $\mathrm{StO}_{2}$ indices with higher peak hsTnT which was dichotomised in high/low categories using median peak hsTnT in the study population as cut-off. Univariable and multivariable logistic regression was used to test the association between $\mathrm{StO}_{2}$ indices and MINS and the adjusted prediction for TW AUC for $\mathrm{SmO}_{2}$ and MINS was calculated. Variables for adjustment in the multivariable analyses were age, sex, body mass index, smoking, diabetes, hypertension, previous stroke, chronic lung disease, arrhythmia, valvular disease, chronic kidney disease, length of surgery, osteotomy performed, estimated blood loss, mean arterial blood pressure and mean heart rate.

Stata Statistical Software (release V.15; StataCorp) was used for all analyses.

\section{Patient and public involvement}

Patients or the public were not involved in the design, conduct, reporting or dissemination plans of this study.

\section{RESULTS}

A total of 70 patients undergoing spine surgery was included in this prospective cohort study. Mean age was $65(33 ; 85)$ years and $41(59 \%)$ participants were female. Mean $(95 \% \mathrm{CI})$ risk of cardiac complications at 30 days after surgery, calculated according to RCRI was 7.7 (7.0 to 8.3$) \%$. The median percentage estimated blood loss of estimated blood volume was 17 (IQR 8-31) \%. A summary of patient characteristics, medical history, surgical information and values for $\mathrm{StO}_{2}$ are found in table 1 .

\section{Incidence of MINS and major outcomes}

The median peak hsTnT was 19 (IQR 10-30) ng/L and based on a hsTnT of 20 to $<65 \mathrm{ng} / \mathrm{L}$ with an absolute change $\geq 5 \mathrm{ng} / \mathrm{L}$ or a single hsTnT $\geq 65 \mathrm{ng} / \mathrm{L}, 28(40 \%)$ participants had MINS (table 2). The number of participants with any postoperative complications were 41 (59\%) and when MINS was included as a complication, $52(74 \%)$ of participants had one or more postoperative complications (table 2). Estimated blood loss and length of surgery was associated with MINS (OR $(95 \% \mathrm{CI}): 1.001$ (1.000 to 1.002 ), $\mathrm{p}=0.002$ and 1.007 (1.002 to 1.011 ), $\mathrm{p}=0.004$, respectively).

\section{Relationships of $\mathrm{StO}_{2}$ to MINS and other outcomes}

In the univariable correlation analysis of TW AUC for $\mathrm{SmO}_{2}$ and peak hsTnT, no significant association was found $\left(r_{s}=0.17, p=0.16\right.$, figure 1$)$. There was a statistically significant association between higher TW AUC for $\mathrm{SmO}_{2}$ and the composite outcome of postoperative complications (participants in lower half: $21(60 \%)$ vs participants in upper half: $31(89 \%), p=0.006$, table 2) but when logistic regression was performed, this association was not significant. Furthermore, a statistically significant association between higher TW AUC for $\mathrm{SmO}_{2}$ and ICU admission was found (participants in lower half: 14 (40\%) vs participants in upper half: 25 (71\%), $\mathrm{p}=0.008$, table 2). There were no other statistically significant differences in outcomes between the two groups based on median TW AUC for $\mathrm{SmO}_{2}$. When testing the $\mathrm{StO}_{2}$ indices as predictors for higher peak hsTnT by logistic regression, the univariable analysis found that for every $1 \%$ increase in median and maximum $\mathrm{SmO}_{2}$, the odds of having high peak hsTnT decreased (OR (95\% CI): 0.93 ( 0.87 to 0.996$), p=0.039$ and 0.92 ( 0.85 to 0.99 ), $\mathrm{p}=0.025$, respectively, table 3$)$. After multivariable adjustment for baseline and clinical variables, median and maximum $\mathrm{SmO}_{2}$ were not independent predictors for higher peak hsTnT (table 3). None of the $\mathrm{StO}_{2}$ indices were found to be significant predictors for MINS (table 3). Adjusted predicted probability was calculated based on univariable logistic regression and showed increasing probability for MINS with increasing TW AUC for $\mathrm{SmO}_{2}$ (figure 2) although this was not statistically significant (OR (95\% CI): 1.00 (0.99 to 1.01), $\mathrm{p}=0.74)$. Although this was not systematically assessed for the purpose of this study, only one participant presented with ischaemic symptoms on the first two postoperative days according to medical records. This patient was not diagnosed with clinical myocardial infarction after examination, although hsTnT was $31 \mathrm{ng} / \mathrm{L}$. 
Table 1 Participant characteristics and intraoperative data

\begin{tabular}{|c|c|}
\hline Variables & Participants $\mathrm{n}=70$ \\
\hline \multicolumn{2}{|l|}{ Demographics } \\
\hline Age, years & $65(33 ; 85)$ \\
\hline Sex, female & $41(59 \%)$ \\
\hline $\mathrm{BMI}, \mathrm{kg} / \mathrm{m}^{2}$ & $28.8(24.4 ; 32.9)$ \\
\hline \multicolumn{2}{|l|}{ ASA } \\
\hline I & $1(1 \%)$ \\
\hline II & $37(53 \%)$ \\
\hline III & $31(44 \%)$ \\
\hline IV & $1(1 \%)$ \\
\hline \multicolumn{2}{|l|}{ Smoking } \\
\hline Never & $37(53 \%)$ \\
\hline Current & $3(4 \%)$ \\
\hline Former & $30(43 \%)$ \\
\hline \multicolumn{2}{|l|}{ Medical history } \\
\hline Stroke & $5(7 \%)$ \\
\hline $\mathrm{TCl}$ & $3(4 \%)$ \\
\hline Hypertension & $36(51 \%)$ \\
\hline Diabetes mellitus & $8(11 \%)$ \\
\hline Chronic lung disease* & $15(21 \%)$ \\
\hline Sleep apnoea & $16(23 \%)$ \\
\hline Arrhythmia & $11(16 \%)$ \\
\hline Valvular disease & $6(9 \%)$ \\
\hline Coronary artery disease & $8(11 \%)$ \\
\hline Creatinine elevation & $2(3 \%)$ \\
\hline \multicolumn{2}{|l|}{ RCRI class } \\
\hline 1 & $49(70 \%)$ \\
\hline II & $15(21 \%)$ \\
\hline III & $6(9 \%)$ \\
\hline IV & 0 \\
\hline
\end{tabular}

Surgical information

\begin{tabular}{|ll|}
\hline Length of surgery, minutes & $264(201 ; 405)$ \\
\hline Osteotomy performed & $35(50 \%)$ \\
\hline Estimated blood loss, $\mathrm{mL}$ & $753(400 ; 1400)$ \\
\hline Mean arterial pressure, $\mathrm{mmHg}$ & $83 \pm 9$ \\
\hline Heart rate, bpm & $69 \pm 11$ \\
\hline
\end{tabular}

Tissue oximetry

\begin{tabular}{|c|c|}
\hline $\mathrm{SmO}_{2}$ median, $\%$ & $75(70 ; 79)$ \\
\hline $\mathrm{SmO}_{2}$ minimum, \% & $66(61 ; 70)$ \\
\hline $\mathrm{SmO}_{2}$ maximum, \% & $84(78 ; 88)$ \\
\hline TW AUC for $\mathrm{SmO}_{2}, \% \times \min /$ hour & $98(9 ; 298)$ \\
\hline $\mathrm{ScO}_{2}$ median, \% & $66(62 ; 71)$ \\
\hline $\mathrm{ScO}_{2}$ minimum, $\%$ & $60(56 ; 65)$ \\
\hline $\mathrm{ScO}_{2}$ maximum, $\%$ & $77(72 ; 82)$ \\
\hline TW AUC for $\mathrm{ScO}_{2}, \%^{*} \mathrm{~min}^{\star} \mathrm{h}^{-1}$ & $33(0.06 ; 131)$ \\
\hline
\end{tabular}

Continued
Table 1 Continued

Variables

Participants $\mathrm{n}=70$

Data are mean $\pm S D$ for normally distributed variables and median (IQR) for variables with skewed distributions.

*Includes asthma and chronic obstructive pulmonary disease. ASA, American society of Anesthesiologists; BMI, body mass index; RCRI, Revised Cardiac Risk Index; $\mathrm{ScO}_{2}$, cerebral tissue oxygenation; $\mathrm{SmO}_{2}$, skeletal muscle tissue oxygenation; $\mathrm{TCl}$, transient cerebral ischaemia; TW AUC, time-weighted area under the curve.

\section{DISCUSSION}

In a prospective cohort study of 70 participants, we investigated intraoperative $\mathrm{StO}_{2}$ as predictor for myocardial injury after spine surgery. We found that $\mathrm{SmO}_{2}$ and $\mathrm{ScO}_{2}$ were not independent predictors for elevated hsTnT or MINS. However, in exploratory analyses, some other indices for $\mathrm{SmO}_{2}$ were associated with higher peak hsTnT, whereas $\mathrm{ScO}_{2}$ indices were not.

$\mathrm{StO}_{2}$ is a result of the oxygen supply and demand of the specific tissue and is determined by multiple physiological factors including oxygen saturation, haemoglobin (Hgb) concentration and cardiac output. ${ }^{17}$ Measurement of $\mathrm{StO}_{2}$ with NIRS has been investigated in previous studies as predictor for a number of different outcomes. Several studies have examined cerebral oxygenation in patients undergoing cardiac surgery, whereas few studies have investigated $\mathrm{SmO}_{2}$ as predictor for clinical outcomes. In patients undergoing cardiac surgery, $\mathrm{ScO}_{2}$ was found to be associated with stroke, cognitive decline, length of hospital stay and mortality. ${ }^{18} 19$ One study found that decrease in $\mathrm{ScO}_{2}$ was not a predictor for delirium in elderly patients. ${ }^{20} \mathrm{~A}$ recent meta-analysis of 10 trials with a total of 1466 patients, found that NIRS-based algorithms for $\mathrm{ScO}_{2}$ did not reduce mortality or organ injury affecting the heart, brain or kidneys. ${ }^{21}$ Despite the lack of evident benefit for $\mathrm{ScO}_{2}$-guided clinical algorithms, $\mathrm{ScO}_{2}$ monitoring is routinely used in cardiac surgery.

Cerebral and skeletal muscle tissue have different physiological characteristics. Meng et al ${ }^{12}$ found that $\mathrm{SmO}_{2}$ was a stronger predictor than $\mathrm{ScO}_{2}$ for composite postoperative outcomes, including myocardial injury, stroke, pulmonary complications and creatinine elevation. Although findings in the current study were statistically insignificant, the exploratory analyses yielded a stronger association between $\mathrm{SmO}_{2}$ and outcomes as compared with $\mathrm{ScO}_{2}$. This aligns with the theory that $\mathrm{SmO}_{2}$ is a leading indicator for global desaturation due to low autoregulation in skeletal muscle tissue compared with the higher level of autoregulation in cerebral tissue. ${ }^{22}$ Of note, skeletal and myocardial autoregulation may not be the same and it is possible that myocardial autoregulation shows similar patterns to cerebral autoregulation in some physiological instances. The importance of preserved cerebral autoregulation is substantial. Brain tissue is more sensitive to hypoxia than skeletal muscle. ${ }^{17}$ One study showed that impaired cerebrovascular autoregulation was 
Table 2 Summary of postoperative outcomes within 30 days after spinal surgery

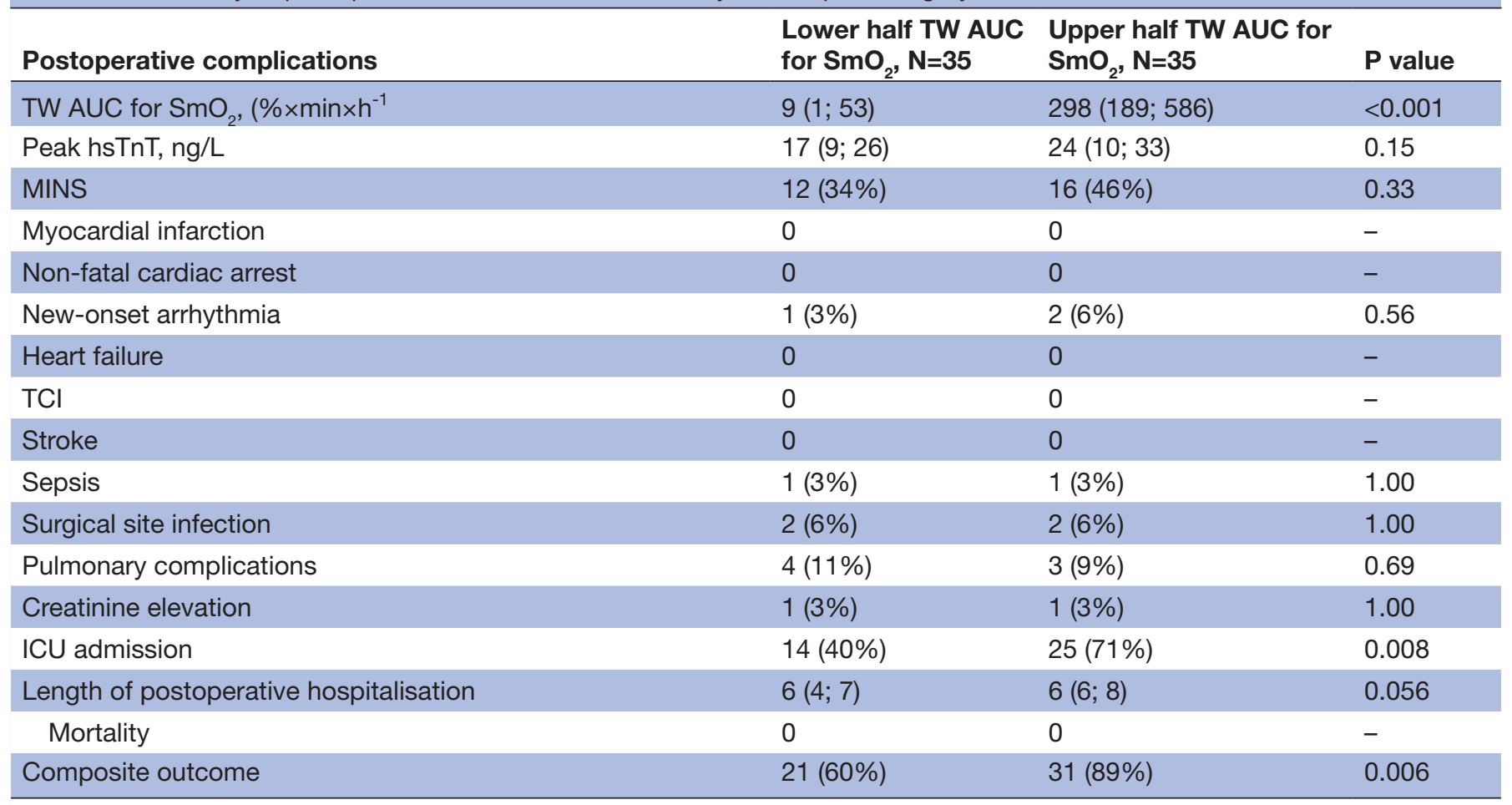

Data are mean \pm SD for normally distributed variables and median (IQR) for variables with skewed distributions). $P$ values are based on $\chi^{2}-$ tests, ANOVA and Wilcoxon rank-sum tests.

ANOVA, analysis of variance; hsTnT, high-sensitivity troponin T; ICU, intensive care unit; MINS, myocardial injury after non-cardiac surgery; $\mathrm{SmO}_{2}$, skeletal muscle tissue oxygenation; TCI, transient cerebral ischaemia; TW AUC, time-weighted area under the curve.

associated with increased morbidity and mortality within 30 days from surgery in patients undergoing major noncardiac surgery. ${ }^{23}$ A study in healthy subjects suggested $\mathrm{SmO}_{2}$ to be an early indicator for impending cardiovascular collapse and showed that $\mathrm{SmO}_{2}$ declined in parallel with stroke volume. ${ }^{24}$ Perfusion of skeletal muscle tissue follows the same linearity in decline with decreasing cardiac output whereas cerebral tissue perfusion only

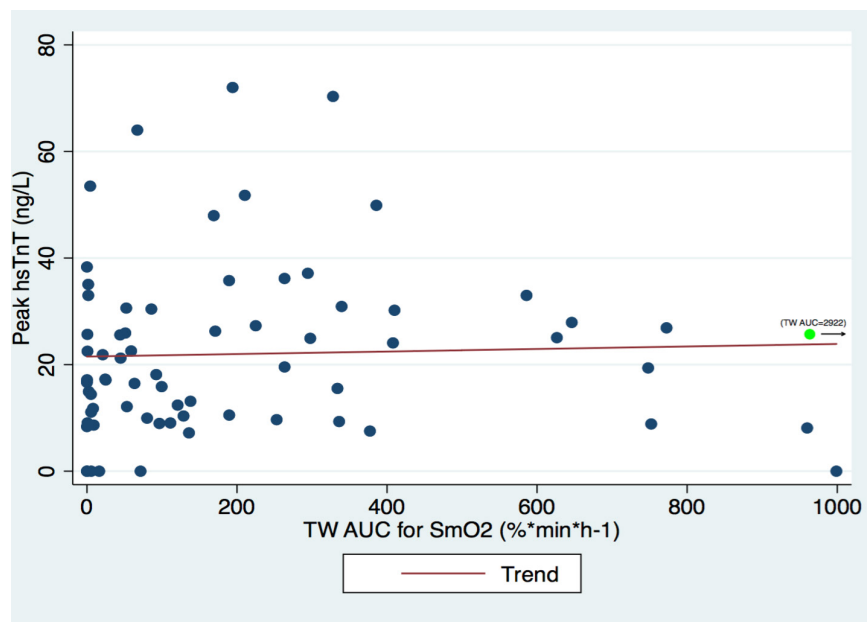

Figure 1 Relationship between time-weighted area under the curve (TW AUC) for skeletal muscle tissue oxygenation $\left(\mathrm{SmO}_{2}\right)$ and peak value of high-sensitivity troponin $\mathrm{T}$ (hsTnT) measured within the first 2 days after surgery. decreases approximately one-third of cardiac output. ${ }^{25}$ This study found TW AUC for $\mathrm{SmO}_{2}$ to be almost three times larger than TW AUC for $\mathrm{ScO}_{2}$ (98\% vs $33 \% \times$ min/ hour) indicating autoregulation in brain tissue. Of note, spine surgery patients at UCSF almost all receive anaesthetics that include very low amounts of inhalational anaesthetics, probably preserving brain autoregulation of blood flow. Despite these findings, the clinical implications of $\mathrm{SmO}_{2}$ monitoring is still yet to be determined. TW AUC for $\mathrm{SmO}_{2}$ was chosen as a predictor in this study as it maximises sensitivity by including all available data for the specific parameter (magnitude and duration of desaturation as well as covering the entire duration of surgery). Furthermore, it minimises the effect of potential error measurements on the $\mathrm{StO}_{2}$ value but because TW AUC for $\mathrm{SmO}_{2}$ is a calculated value it currently has limitations in regards of clinical utility.

$\mathrm{StO}_{2}$ was not statistically significant associated with MINS in the current study but other indicators of supply-demand mismatch, that is, estimated blood loss and length of surgery, were significantly associated with MINS and peak hsTnT. These are established predictors for MINS $^{26}$ and contributes to the understanding of the pathophysiology for elevated troponin. ${ }^{27}$

In general, the majority of MINS are undetected $(80 \%)$ as patients do not have ischaemic symptoms. ${ }^{40}$ In this study, only one participant presented with ischaemic symptoms. The type of surgery the participants underwent 
Table $3 \mathrm{StO}_{2}$ measures as predictors for higher peak hsTnT and MINS

\begin{tabular}{|c|c|c|c|c|c|c|}
\hline \multirow[b]{2}{*}{$\mathrm{StO}_{2}$ indices } & \multicolumn{4}{|c|}{ High peak hsTnT versus low peak hsTnT } & \multicolumn{2}{|c|}{ MINS versus no MINS } \\
\hline & $\begin{array}{l}\text { Univariable } \\
\text { OR }(95 \% \mathrm{Cl})\end{array}$ & $P$ value & $\begin{array}{l}\text { Multivariable } \\
\text { OR }(95 \% \mathrm{Cl})\end{array}$ & $P$ value & $\begin{array}{l}\text { Univariable } \\
\text { OR }(95 \% \mathrm{Cl})\end{array}$ & $P$ value \\
\hline Median $\mathrm{SmO}_{2}, \%$ & 0.93 (0.87 to 0.996$)$ & 0.039 & $0.92(0.82$ to 1.04$)$ & 0.18 & 0.96 (0.76 to 1.21$)$ & 0.75 \\
\hline Minimum $\mathrm{SmO}_{2}, \%$ & 0.97 (0.92 to 1.01) & 0.16 & 0.94 (0.86 to 1.03$)$ & 0.20 & 0.95 (0.75 to 1.22$)$ & 0.70 \\
\hline Maximum $\mathrm{SmO}_{2}, \%$ & 0.92 (0.85 to 0.99$)$ & 0.025 & 0.90 (0.80 to 1.02$)$ & 0.11 & 0.90 (0.70 to 1.15$)$ & 0.41 \\
\hline TW AUC $\mathrm{SmO}_{2}, \% \times \min \times \mathrm{h}^{-1}$ & 1.00 (1.00 to 1.00$)$ & 0.15 & $1.00(1.00$ to 1.01$)$ & 0.22 & 1.00 (0.99 to 1.01$)$ & 0.74 \\
\hline Median $\mathrm{ScO}_{2}, \%$ & 0.99 (0.91 to 1.06$)$ & 0.70 & 0.92 (0.79 to 1.06$)$ & 0.24 & 0.79 (0.59 to 1.07$)$ & 0.13 \\
\hline Minimum $\mathrm{ScO}_{2}, \%$ & 0.96 (0.91 to 1.03$)$ & 0.26 & 0.83 (0.69 to 0.98$)$ & 0.030 & 0.10 (0.00 to 5.34$)$ & 0.26 \\
\hline Maximum $\mathrm{ScO}_{2}, \%$ & 0.97 (0.90 to 1.05$)$ & 0.47 & 0.99 (0.94 to 1.05$)$ & 0.82 & 1.01 (0.96 to 1.06$)$ & 0.76 \\
\hline TW AUC $\mathrm{ScO}_{2}, \% \times \min \times \mathrm{h}^{-1}$ & 1.00 (1.00 to 1.01$)$ & 0.32 & 1.00 (1.00 to 1.01$)$ & 0.33 & 1.00 (1.00 to 1.01$)$ & 0.32 \\
\hline
\end{tabular}

This table shows the odds of having an outcome (high peak hsTnT or MINS, respectively) for every 1\%/one unit increase in the specific $\mathrm{StO}_{2}$ variable. Multivariable analysis is adjusted for age, sex, BMI, smoking, diabetes, hypertension, previous stroke, chronic lung disease, arrhythmia, valvular disease, chronic kidney disease, length of surgery, osteotomy performed, estimated blood loss, mean arterial blood pressure and mean heart rate.

BMI, body mass index; hsTnT, high-sensitivity troponin T; MINS, myocardial injury after non-cardiac surgery; $\mathrm{ScO}_{2}$, cerebral tissue oxygenation; $\mathrm{SmO}_{2}$, skeletal muscle tissue oxygenation; StO2, tissue oxygenation; TW AUC, time-weighted area under the curve.

was comprehensive and many participants were treated with strong analgesics postoperatively which could be a contributing factor to the lack of ischaemic symptoms in the participants with MINS. The incidence of MINS among the participants in this study was $40 \%$. In comparison the general incidence of MINS in patients undergoing non-cardiac surgery is $8 \%{ }^{4}$ but this is not restricted to major surgery only and the incidence depends on the cut-off for troponin elevation used. Other groups found similar high incidence of MINS. ${ }^{28}$

\section{Study limitations}

As this was an observational cohort study it was not designed to determine causality between $\mathrm{StO}_{2}$ and postoperative myocardial injury. The study was not powered for all secondary outcomes, as we based the power

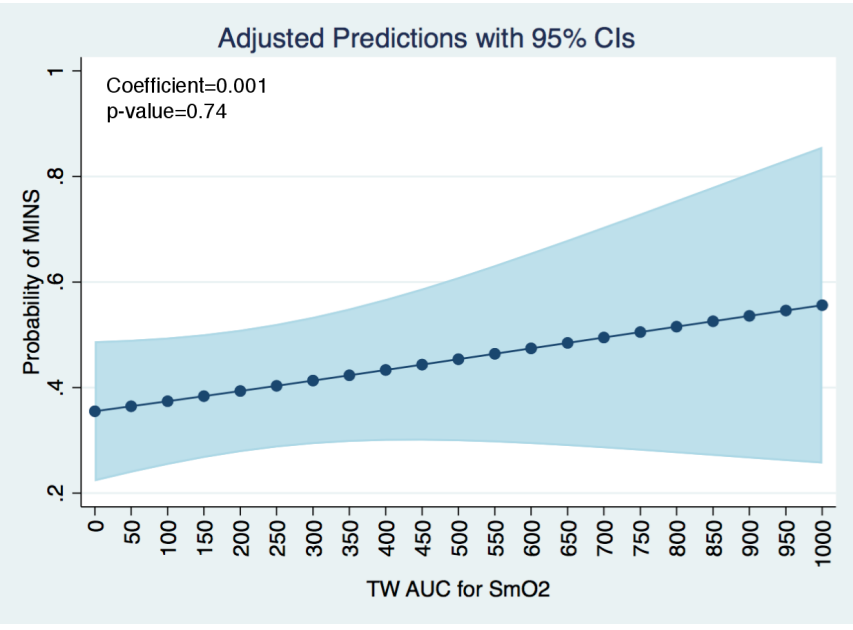

Figure 2 Adjusted prediction curve for time-weighted area under the curve (TW AUC) for skeletal muscle tissue oxygenation $\left(\mathrm{SmO}_{2}\right)$ as predictor for myocardial injury after non-cardiac surgery (MINS). calculation on a study with the outcome composite postoperative complications that included less severe complications (constipation, oliguria, etc). ${ }^{12}$

We found a high incidence of MINS in this study but the number of serious outcome events (eg, death, stroke, non-fatal cardiac, myocardial infarction) were sparse in the 30-day follow-up period. The participants underwent spine surgery which was not emergent, conducted as cancer treatment/tumour resection or indicated by any life-threatening condition. Thus, it is possible that participants were in a better physical condition when scheduled for this type of elective surgery than for other major noncardiac surgical procedures. Changes in blood pressure and heart rate may trigger MINS. Extensive analyses of associations between these parameters an MINS were not possible in this study.

The NIRS method is non-invasive and tracks $\mathrm{StO}_{2}$ continuously. However, limitations in regard to the technology has been presented and includes bias regarding skin pigmentation, gender and assumed mixture of venous and arterial blood. ${ }^{29}$ With the equipment used in this study it was not possible to obtain data on different Hgb fractions (total Hgb, oxy-Hgb and deoxy-Hgb), which could potentially have qualified the analysis even further. Total blood loss was included in the predefined model to predict MINS but relative changes in Hgb concentrations, including those caused by transfusions, was not accounted for. Interindividual differences in saturation contributes to the difficulty of determining an absolute threshold for tissue hypoxia. In the calculation of the primary predictor of TW AUC for $\mathrm{SmO}_{2}$ we used the population median for intraoperative $\mathrm{SmO}_{2}$ as cut-off. The choice of cut-off should be considered when interpreting results of studies investigating the impact of $\mathrm{StO}_{2}$.

In summary, in this study $\mathrm{StO}_{2}$ was not a statistically significant predictor for peak postoperative hsTnT but 
is a potential predictor for other postoperative complications. Future studies should focus on determining a threshold for $\mathrm{StO}_{2}$ taking interindividual factors into account and apply NIRS technology with the ability of detecting different $\mathrm{Hgb}$ fractions. The frequency of MINS was high $(40 \%)$ and related to blood loss, suggesting supply-demand mismatch aetiology in spine surgery. $\mathrm{StO}_{2}$ did not have the power to predict myocardial injury but other intraoperative indicators for supply-demand mismatch should be considered as potential predictors for MINS in future studies.

Contributors All authors participated in the initial drafting of the manuscript as well as the revised manuscript. All authors met the ICMJE criteria for authorship. Below is specification of author contributions: KFB: Conception and design, acquisition, analysis and interpretation of data, drafting, critical revision and final approval of the manuscript. CSM: Conception and design, analysis and interpretation of data, critical revision and final approval of the manuscript. PB: Conception and design, analysis and interpretation of data, critical revision and final approval of the manuscript.

Funding This work was supported by a grant from the Lundbeck Foundation Clinical Research Fellowship 2017-2018 for Katrine Feldballe Bernholm. Grant number not applicable. CAS Medical Systems provided the FORE-SIGHT ELITE Tissue 0ximeter and probes at no cost.

Competing interests CSM has received institutional direct and indirect research funding from Boehringer Ingelheim, Ferring Pharmaceuticals, Radiometer and Merch, Sharp \& Dohme, as well as lecture fees from Radiometer, all outside submitted work. The remaining authors declare that they have no conflict of interest.

Patient and public involvement Patients and/or the public were not involved in the design, or conduct, or reporting, or dissemination plans of this research.

Patient consent for publication Not required.

Ethics approval The study was approved by the University of California San Francisco Institutional Review Board (IRB 14-12996) and both verbal and written consent was obtained from all participants before surgery.

Provenance and peer review Not commissioned; externally peer reviewed.

Data availability statement Data are available on reasonable request. Anonymised data will be made available upon reasonable request.

Open access This is an open access article distributed in accordance with the Creative Commons Attribution Non Commercial (CC BY-NC 4.0) license, which permits others to distribute, remix, adapt, build upon this work non-commercially, and license their derivative works on different terms, provided the original work is properly cited, appropriate credit is given, any changes made indicated, and the use is non-commercial. See: http://creativecommons.org/licenses/by-nc/4.0/.

\section{ORCID iDs}

Katrine Feldballe Bernholm http://orcid.org/0000-0001-5324-9430

Christian S. Meyhoff http://orcid.org/0000-0002-4885-4609

Philip Bickler http://orcid.org/0000-0002-5077-4982

\section{REFERENCES}

1 Mrkobrada M, Hill MD, Chan MTV, et al. Covert stroke after non-cardiac surgery: a prospective cohort study. Br J Anaesth 2016;117:191-7.

2 Sanaiha Y, Juo Y-Y, Aguayo E, et al. Incidence and trends of cardiac complications in major abdominal surgery. Surgery 2018;164:539-45.

3 Devereaux PJ, Sessler DI. Cardiac complications in patients undergoing major noncardiac surgery. N Engl J Med Overseas Ed 2015;373:2258-69.

4 Botto F, Alonso-Coello P, Chan MT. Myocardial injury after noncardiac surgery: a large, international, prospective cohort study establishing diagnostic criteria, characteristics, predictors, and 30day outcomes. Anesthesiology 2014;120:564-78.

5 Devereaux PJet al. Characteristics and short-term prognosis of perioperative myocardial infarction in patients undergoing noncardiac surgery. Ann Intern Med 2011;154:523-8.

6 van Waes JAR, Nathoe HM, de Graaff JC, et al. Myocardial injury after noncardiac surgery and its association with short-term mortality. Circulation 2013;127:2264-71.

7 Devereaux PJ, Chan M, Alonso-Coello P. Association between postoperative troponin levels and 30-day mortality among patients undergoing noncardiac surgery. J Am Med Assoc 2012;307:2295-304.

8 Devereaux PJ, Biccard BM, Sigamani A. Association of postoperative high-sensitivity troponin levels with myocardial injury and 30-day mortality among patients undergoing noncardiac surgery. Jama 2017;317:1642.

9 Mashour GA, Shanks AM, Kheterpal S. Perioperative stroke and associated mortality after noncardiac, nonneurologic surgery. Anesthesiology 2011;114:1289-96.

10 Puelacher C, Buse GL, Seeberger D. Perioperative myocardial injury after noncardiac surgery incidence, mortality, and characterization. Circulation 2018;137:1221-32.

11 Kahn J, Alonso-Coello P, Devereaux PJ. Myocardial injury after noncardiac surgery. Curr Opin Cardiol 2014;67:794-6.

12 Meng L, Xiao J, Gudelunas K, et al. Association of intraoperative cerebral and muscular tissue oxygen saturation with postoperative complications and length of hospital stay after major spine surgery: an observational study. Br J Anaesth 2017;118:551-62.

13 Abdelmalak BB, Cata JP, Bonilla A, et al. Intraoperative tissue oxygenation and postoperative outcomes after major non-cardiac surgery: an observational study †. Br J Anaesth 2013;110:241-9.

14 Kavsak PA, Walsh M, Srinathan S, et al. High sensitivity troponin $\mathrm{T}$ concentrations in patients undergoing noncardiac surgery: a prospective cohort study. Clin Biochem 2011;44:1021-4.

15 Giannitsis E, Kurz K, Hallermayer K, et al. Analytical validation of a high-sensitivity cardiac troponin T assay. Clin Chem 2010;56:254-61.

16 Duceppe E, Parlow J, MacDonald P, et al. Canadian cardiovascular Society guidelines on perioperative cardiac risk assessment and management for patients who undergo noncardiac surgery. Canadian Journal of Cardiology 2017;33:17-32.

17 Leach RM, Treacher DF. Oxygen transport. Tissue hypoxia. BMJ 1998;317:1370-3.

18 Scheeren TWL, Schober P, Schwarte LA. Monitoring tissue oxygenation by near infrared spectroscopy (NIRS): background and current applications. J Clin Monit Comput 2012;26:279-87.

19 Casati A, Fanelli G, Pietropaoli P, et al. Monitoring cerebral oxygen saturation in elderly patients undergoing general abdominal surgery: a prospective cohort study. Eur J Anaesthesiol 2007;24:59-65.

20 Soh S, Shim J-K, Song J-W, et al. Postoperative delirium in elderly patients undergoing major spinal surgery: role of cerebral oximetry. $J$ Neurosurg Anesthesiol 2017;29:426-32.

21 Serraino GF, Murphy GJ. Effects of cerebral near-infrared spectroscopy on the outcome of patients undergoing cardiac surgery: a systematic review of randomised trials. BMJ Open 2017;7:e016613.

22 Bickler P, Feiner J, Rollins M, et al. Tissue oximetry and clinical outcomes. Anesth Analg 2017;124:72-82.

23 Chuan A, Short TG, Peng AZY, et al. Is cerebrovascular autoregulation associated with outcomes after major noncardiac surgery? A prospective observational pilot study. Acta Anaesthesiol Scand 2019;63:1-10.

24 Soller BR, Yang Y, Soyemi OO, et al. Noninvasively determined muscle oxygen saturation is an early indicator of central hypovolemia in humans. J Appl Physiol 2008;104:475-81.

25 Meng L, Hou W, Chui J, et al. Cardiac output and cerebral blood flow. Anesthesiology 2015;123:1198-208.

26 Grobben RB, van Klei WA, Grobbee DE, et al. The aetiology of myocardial injury after non-cardiac surgery. Neth Heart $J$ 2013;21:380-8.

27 Sandoval Y, Smith SW, Thordsen SE, et al. Supply/Demand type 2 myocardial infarction. J Am Coll Cardiol 2014;63:2079-87.

28 Lurati Buse GAL, Schumacher P, Seeberger E, et al. Randomized comparison of sevoflurane versus propofol to reduce perioperative myocardial ischemia in patients undergoing noncardiac surgery. Circulation 2012;126:2696-704.

29 Bickler PE, Feiner JR, Rollins MD. Factors affecting the performance of 5 cerebral oximeters during hypoxia in healthy volunteers. Anesth Analg 2013;117:813-23. 